\title{
Gusto y promoción en el contexto cortesano. Los condes de Miranda en el tránsito a la Contemporaneidad
}

\author{
Taste and promotion in the courtly context. The counts of Miranda \\ in the transition to the Contemporary Age
}

\author{
María José ZAPARAÍN YÁÑEZ \\ Universidad de Burgos \\ ORCID: https://orcid.org/0000-0002-1443-4964 / mjzaparain@ubu.es \\ Juan ESCORIAL ESGUEVA \\ Universidad de Salamanca \\ ORCID: https://orcid.org/0000-0002-7045-9170 / juanescorial@usal.es \\ DOI: http://dx.doi.org/10.18002/da.v0i18.5896
}

Recibido: 14-IV-2019

Aceptado: 5-VII-2019

RESUMEN: La familia de los condes de Miranda constituye un singular exponente de las transformaciones experimentadas por la alta nobleza entre el final de la Edad Moderna y los inicios del mundo contemporáneo. En este proceso, su promoción artística se convirtió en un elocuente testimonio de su adaptación al paso del tiempo. Las importantes empresas que llevaron a cabo, tanto en Madrid como en sus fundaciones burgalesas, reflejan la apuesta por destacados profesionales y sus relaciones con los círculos académicos. Todo ello pone de manifiesto, a través de su gusto y sus trayectorias personales, la evolución entre el recuerdo del pasado y el triunfo del individuo, así como el aprecio de los valores estéticos como marca de identidad nobiliaria.

Palabras clave: condes de Miranda; Madrid; Peñaranda de Duero (Burgos); La Aguilera (Burgos); José de Hermosilla; Ventura Rodríguez; Agustín Esteve.

ABSTRACT: The Counts of Miranda's lineage is an exponent of the transformations that affected the idea of nobility in the end of the Modern Age and the beginning of the Contemporary world. Their artistic promotion in Madrid and Burgos shows their adaptation to the changes and reflects how they tasked their projects to renowned artists with academic relationship and reveals the social transformations in this period. Their personal trajectories shows the evolution of their own history and the value of artistic expressions to identify their social position.

Keywords: Counts of Miranda; Madrid; Peñaranda de Duero (Burgos); La Aguilera (Burgos); José de Hermosilla; Ventura Rodríguez; Agustín Esteve.

Entre el inicio de la Modernidad y los compases finales del absolutismo borbónico, la casa condal de Miranda del Castañar configuró, a través de diferentes actuaciones, un importante legado en el que la tradición y la adaptación a los nuevos tiempos conformaron sus señas de identidad según las pautas 
propias del momento ${ }^{1}$. Sin embargo, tan amplio marco temporal estuvo definido por periodos de esplendor y otros de profunda atonía, en los cuales, sin embargo, no se permitió que la herencia de sus antepasados se perdiera, siendo una constante inspiración para quienes ostentaron el título familiar.

Este había sido concedido, en 1457, a Diego López de Zúñiga y, desde sus inicios, se vinculó a la villa burgalesa de Peñaranda de Duero, en la que sus titulares llevaron a cabo una singular actividad promotora, que permitió transformar la fisonomía del territorio bajo su control y proyectar una sólida imagen del linaje. En esta faceta sobresalieron los III condes de Miranda que, entre otras empresas, iniciaron la construcción del palacio familiar y la capilla mayor del monasterio de La Vid, a las que se sumaría, tras la muerte del conde, la colegiata de Santa $\mathrm{Ana}^{2}$. Las obras fueron continuadas por sus descendientes, entre los que destacan, de forma especial, los VI condes, que lograron culminar gran parte de estos ambiciosos proyectos.

No obstante, desde principios del siglo XVII, la familia trasladó su residencia a la corte madrileña $\mathrm{y}$, si bien se mantuvieron vinculados a sus fundaciones burgalesas, estas quedaron al margen de sus prioridades. En las primeras décadas del setecientos, los XII condes de Miranda, José Joaquín López de Zúñiga e Isabel Rosa de Ayala, intentaron recuperar parte de ese protagonismo ${ }^{3}$, pero

\footnotetext{
${ }^{1}$ Enrique Soria Mesa, La nobleza en la España moderna. Cambio y continuidad (Madrid: Marcial Pons, 2007), 261-274.

${ }^{2}$ Eduardo Carazo Lefort, "El palacio de los condes de Miranda en Peñaranda de Duero", Academia. Boletín de la Real Academia de Bellas Artes de San Fernando, no 85 (1995), 505-544; Begoña Alonso Ruiz, “De la capilla gótica a la renacentista: Juan Gil de Hontañón y Diego de Siloé en La Vid", Anuario del Departamento de Historia y Teoría del Arte, no 15 (2003), 45-57; M. José Zaparaín Yáñez, "Con otros ojos. La promoción nobiliar femenina en la Ribera burgalesa del Duero. Siglos XVI y XVII", Biblioteca: estudio e investigación, no 28 (2013), 280-289.
}

${ }^{3}$ M. José Zaparaín Yáñez, El monasterio de Santa María de La Vid: arte y cultura. Del medievo a las transfor- la muerte del primero, en 1725, hizo que fuesen sus sucesores, Antonio López de Zúñiga, y el hijo de este, Pedro de Alcántara López de Zúñiga, los encargados de continuar el legado de sus antepasados.

El dilatado marco temporal en el que estuvieron al frente de sus estados les permitió ser testigos de los trascendentales cambios que, con el fin de modernizar la organización del Estado desde las perspectivas de racionalidad y eficacia, definieron los reinados de Felipe V, Fernando VI y Carlos III. De ellos fueron partícipes, tanto por su servicio a la Corona como por el interés que mostraron por las artes y las ciencias. Así lo atestiguan los vínculos que mantuvieron con destacados representantes de las mismas.

A su vez, ambos nobles alcanzaron especial significación en las obras promovidas en la corte madrileña o en las antiguas fundaciones burgalesas, demostrando la voluntad de completar la herencia recibida, actualizarla y mejorarla, siguiendo una línea de actuación que se enmarca en una aceptada corriente sobre la utilización de las artes por parte de las más destacadas familias. En este contexto de cambio, las principales casas nobiliarias transformaron sus hábitos en relación con las obras artísticas, evolucionando desde su utilización para la transmisión de los valores de la nobleza -prestando especial atención al linaje, como fundamento del relato que querían transmitir ${ }^{4}$ - hacia unos nuevos presupuestos. Entre ellos la promoción, el gusto y la proximidad con las Bellas Artes, así como el trato personal con diferentes artistas, fueron empleados como signo de distinción de este grupo social en el que cada

maciones arquitectónicas de los siglos XVII y XVIII (Madrid: Religión y Cultura, 1994), 46-49; M.ํ José Zaparaín Yáñez, Desarrollo artístico de la comarca arandina. Siglos XVII y XVIII (Burgos: Diputación Provincial de Burgos, 2002) II, 377-383, 395-404.

${ }^{4}$ Antonio Urquízar Herrera y José Antonio Vigara Zafra, "La nobleza española y Francia en el cambio de sistema artístico, 1700-1850", en El arte español entre Roma y París (siglos XVIII y XIX). Intercambios artísticos y circulación de modelos (Madrid: Casa de Velázquez, 2014), 266-268. 
vez resultaba más evidente la afirmación del individuo sobre el colectivo familiar y, de ahí, la progresiva sustitución de las propuestas arquitectónicas por el mayor interés en la pintura $y$, especialmente, en el género del retrato ${ }^{5}$.

Estos cambios, fruto de la influencia del ámbito francés, permitieron a algunos nobles redefinir su papel al servicio de la Corona, encontrando en las prestaciones de carácter cultural una nueva vía de diferenciación con respecto a otros grupos sociales emergentes, sustituyendo o completando a la militar o a la burocrática en las que, tradicionalmente, habían obtenido distinciones y honores. Ejemplifican todo ello algunas importantes familias como las de los duques de Alba, los de Osuna o los condes de Fernán Núñez ${ }^{6}$. Por lo que se refiere a los condes de Miranda, a la luz de los datos obtenidos hasta el momento, su comportamiento a lo largo de este periodo parece evidenciar, desde planteamientos mucho más modestos que los anteriores, esta misma evolución. Por ello, se produce, de forma paulatina, una profunda reelaboración de su política artística, desde la actualización y conclusión de los proyectos de sus antepasados a la construcción de una nueva imagen familiar.

\section{RENOVACIÓN DESDE LA TRADI- CIÓN (1725-1765)}

En 1725, Antonio López de Zúñiga (1699-1765) asumió, como XIII conde de Miranda, el control de la casa nobiliar $\mathrm{y}$, a partir de entonces, será el encargado de dirigir las actuaciones que emprenderá su familia. Por ello, a principios del año siguiente, iniciará las reformas del palacio familiar situado en la madrileña plaza de las Carboneras que, posiblemente, respondan a los preparativos para la formalización de un nuevo hogar, en el marco de las transformaciones que las re-

\footnotetext{
${ }^{5}$ Urquízar Herrera y Vigara Zafra, "La nobleza...", 269-270.

${ }^{6}$ Sobre ello, Urquízar Herrera y Vigara Zafra, "La nobleza...", 257-274.
}

sidencias nobiliarias madrileñas experimentaron a lo largo del setecientos ${ }^{7}$. De hecho, en noviembre, contraería matrimonio con María Teresa Girón y Pacheco (1706-1755), hija del V duque de Uceda ${ }^{8}$. Alegando que iba a trasladarse a esta residencia, solicitó permiso para unirla, a través de un pasadizo, con la vecina Casa del Salvaje, también de su propiedad, lo que obtuvo el informe favorable del arquitecto Pedro de Ribera 9 .

Las actuaciones sobre estos edificios continuaron años más tarde, insistiendo en el beneficio público que estas producirían en la plaza, al quedar "...más adornada y vistosa por la buena simetría y unión..." de los dos inmuebles. Aprobada la intervención, esta fue efectuada por el maestro de obras Francisco Ángel acorde a la sencilla traza presentada (Fig. 1) ${ }^{10}$. También se ocupó de la casa que tenía inmediata al monasterio premonstratense de los Afligidos, del que era patrono. En 1732 quiso renovar su fachada y construir un pasadizo que la uniera con aquel, ocupando un terreno que, al no haber sido acotado por sus antepasados, se había convertido en calle pública. El reconocimiento de todo ello fue encomendado al maestro mayor de obras, Pedro de Ribera, y al alarife Francisco Ruiz, quienes no vieron inconveniente en su realización ${ }^{11}$.

En estas residencias dispusieron la amplia colección formada por sus predecesores en la que destacaban lienzos de Ribera, Orrente, Murillo o Sánchez Coello, algunos importantes tapices o los ricos fondos bibliográficos que se habían ido sumando a través

7 Natalia González Heras, "De casas principales a palacio. La adaptación de la residencia nobiliaria madrileña a una nueva cotidianeidad", Revista de Historia Moderna. Anales de la Universidad de Alicante, 30 (2012), 47-66.

${ }^{8}$ Archivo Histórico de la Nobleza (AHNob), Frías, c. 957 , d. $43-47$.

9 Archivo de la Villa de Madrid (AVM), 1-12-49; Matilde Verdú Ruiz, La obra municipal de Pedro de Ribera (Madrid: Ayuntamiento de Madrid, 1988), 112.

\footnotetext{
${ }^{10}$ AVM, 1-12-49.

${ }^{11}$ AVM, 1-17-46; Verdú Ruiz, La obra..., 118-119.
} 


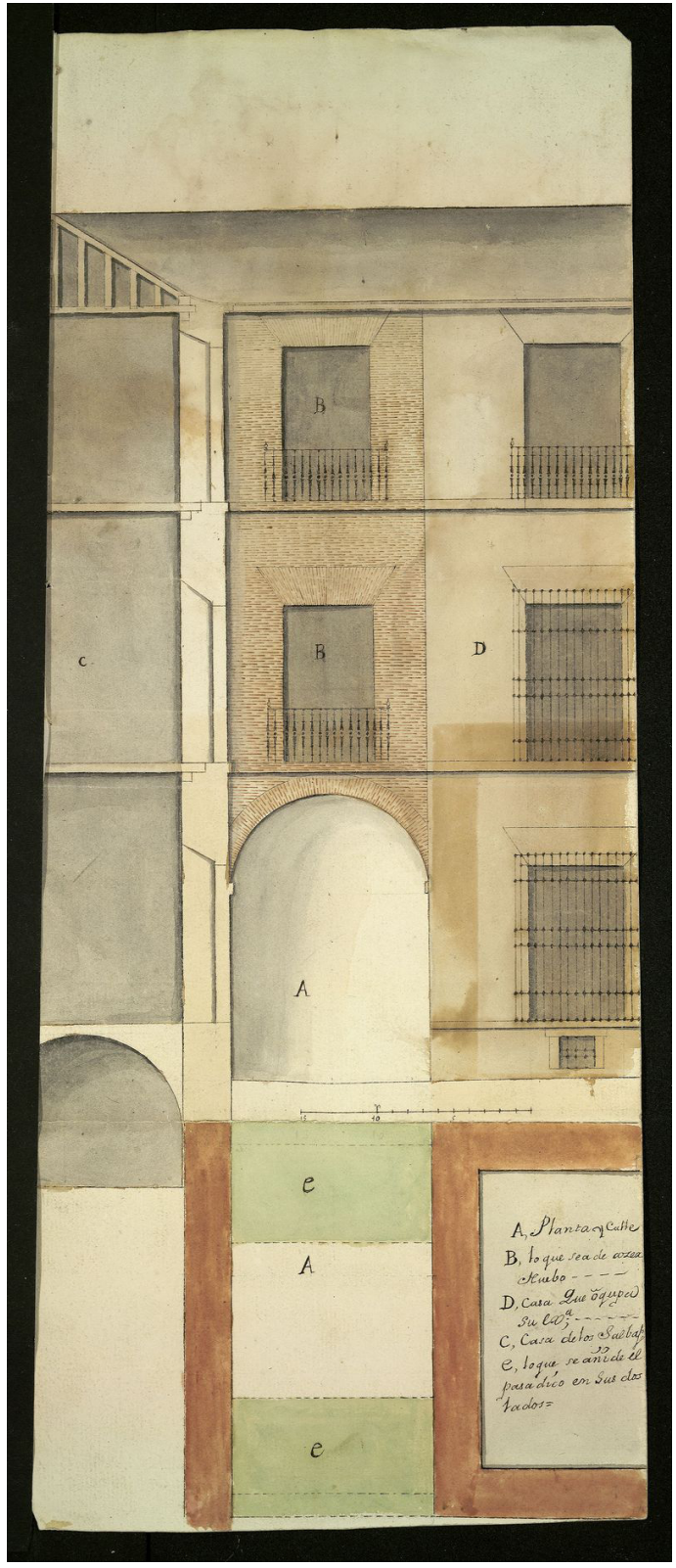

- Fig. 1. Traza del pasadizo de las casas del conde de Miranda en la plaza de las Carboneras de Madrid (1744). Archivo de la Villa de Madrid, 1-12-49 (Licencia Creative Commons)

de diversos entronques familiares ${ }^{12}$. Todo ello conformaría un ambiente heterogéneo

12 Archivo Histórico de Protocolos de Madrid (AHPM), Prot. 18.777; M. a del Mar Nicolás Martínez, "Sobre la procedencia de los paisajes de José de Ribera de la colección Casa de Alba y otras noticias", Archivo Español de Arte, vol. LXXXIX, no 355 (2016), 317-325; Gregorio de Andrés, "Los códices del conde de Miranda en la Biblioteca Nacional", Revista de Archivos, Bibliotecas y Museos, vol. LXXXII, no 4 (1979), 611-627. en el que convivían piezas de muy diversa procedencia, en línea con otras colecciones artísticas del momento ${ }^{13}$.

El conde tampoco olvidó el compromiso con sus posesiones en tierras burgalesas donde la familia había cimentado su esplendor, siendo las fundaciones religiosas las que recibieron una atención preferente. En este sentido, don Antonio buscó la ocasión de dejar una huella expresiva de su aportación particular en aquellas empresas iniciadas por sus predecesores que, o no estaban concluidas, o bien, precisaban de una actualización de sus espacios conforme al ideario de los nuevos tiempos. En cualquier caso, no solo contribuyó a renovar la imagen de su linaje, entendida como un conjunto de aportaciones sucesivas, sino que intentó poner el punto final de un largo proceso a través de propuestas de un claro sentido personalista que concebía como mejoras a las mismas.

Fue la colegiata de Santa Ana, en Peñaranda de Duero, la que priorizó sus desvelos y donde su intervención marcó un hito definitivo en su historia constructiva. En 1728 envió a un maestro para que evaluara su estructura, por el peligro que suponía el no haberse cerrado la zona de poniente, lo que exigió la puesta en práctica de un exhaustivo plan de actuaciones ${ }^{14}$. Su alto coste le llevó a solicitar, en 1731, poder emplear la donación hecha por su madre para el culto al Santísimo Sacramento, recibiendo el permiso del Cabildo interesado en su realización ${ }^{15}$. La finalización se efectuó siguiendo “...la planta que para en el archivo de dicha iglesia junto

${ }^{13}$ Diana Urriagli Serrano, "Coleccionismo de pintura en España en la segunda mitad del siglo XVIII", en $E l$ arte español entre Roma y París (siglos XVIII y XIX). Intercambios artísticos y circulación de modelos (Madrid: Casa de Velázquez, 2014) , 239-240.

${ }^{14}$ M. José Zaparaín Yáñez, “El patronato del conde de Miranda en la iglesia colegial de Peñaranda de Duero, 1728-1732", en Patronos, promotores, mecenas y clientes. VII Congreso Nacional de Historia del Arte (Murcia: Universidad de Murcia, 1992) 581-588; Zaparaín Yáñez, Desarrollo artístico... II, 379-381.

${ }^{15}$ Zaparaín Yáñez, "El patronato...”, 581-583; Zaparaín Yáñez, Desarrollo artístico... II, 380. 
a la de la portada..."16, lo que revela la pretensión de respetar las características con las que se inició su construcción en el siglo XVI. De ahí que se mantuvieran la tipología de los vanos e, incluso, el sistema de cerramiento, a base de bóvedas de crucería, con el fin de guardar la debida "correspondencia" exigida por el concepto de decoro o adecuación al contexto ${ }^{17}$.

No obstante, la portada no se efectuó según el plan custodiado, del que desconocemos sus rasgos definitorios, los cuales, probablemente, no responderían a los gustos de la época. Ello, sin embargo, no afectaría a la valoración del resto de la fábrica, al entenderse el frente como algo superpuesto y no la consecuencia de un proyecto unitario. En este caso se recurrió al reconocido arquitecto benedictino, fray Pedro Martínez de Cardeña ${ }^{18}$, quien concibió la portada como una pieza yuxtapuesta al conjunto del templo, convirtiéndose en el mejor estandarte de la promoción de don Antonio, según figura, tanto en el escudo que la preside como en la cartela que centra la composición, donde consta ostentosamente la identidad de quien “...CONCLVIO Y PERFECZIONO..." el edificio (Fig. 2) ${ }^{19}$.

Al mismo tiempo, el conde utilizó la portada como soporte iconográfico de sus devociones pues, además de la titular del templo -santa Ana-, se encuentran representados su santo patrono y el de la esposa, -santa

${ }^{16}$ Archivo Diocesano de Burgos (ADBu), Peñaranda de Duero, Leg. 32.

${ }^{17}$ Zaparaín Yáñez, "El patronato...", 582-583; Zaparaín Yáñez, Desarrollo artístico... II, 380-381; Javier Gómez Martínez, El gótico español de la Edad Moderna (Valladolid: Universidad de Valladolid, 1998), 209; Emilio Morais Vallejo, "Formas góticas en la arquitectura del Barroco en la provincia de Burgos", Boletín del Seminario de Estudios de Arte y Arqueología, no 79 (2013), 124-126.

${ }^{18}$ Lena S. Iglesias Rouco y M. o José Zaparaín Yáñez, "El monasterio de San Pedro de Cardeña, centro dinamizador del desarrollo artístico burgalés en los primeros decenios del siglo XVIII. Aportación a su estudio", Boletín de la Institución Fernán González, vol. LXXVIII, nº 220 (2000), 107-140.

${ }^{19}$ Zaparaín Yáñez, Desarrollo artístico... II, 381-383.

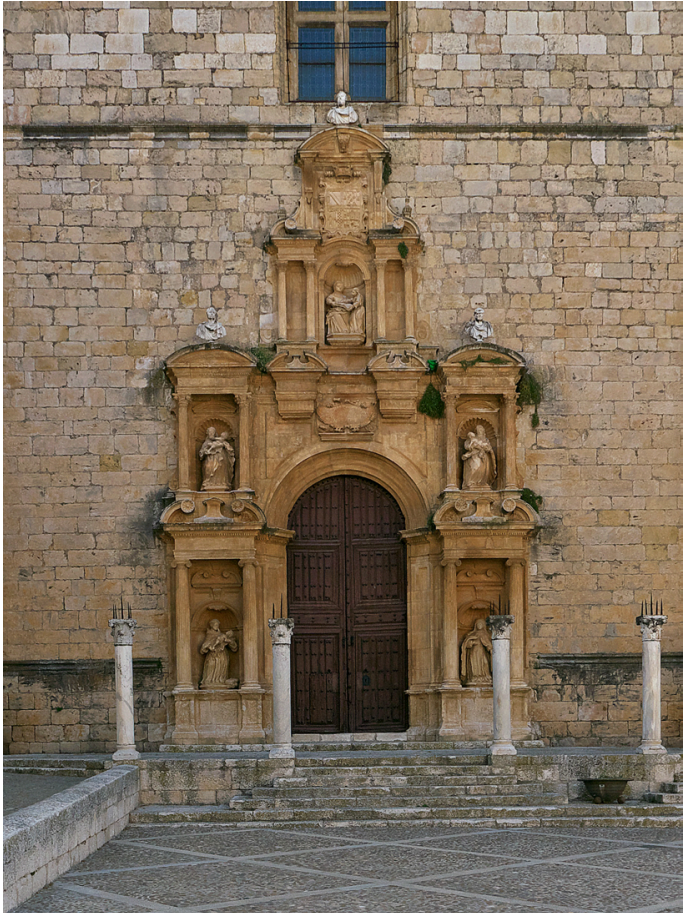

- Fig. 2. Portada de la colegiata de Peñaranda de Duero (Burgos). Fotografía de los autores.

Teresa-, así como las figuras de san Joaquín y san José en recuerdo a su padre. Esta intención programática, en parte inserta entre las devociones de los Zúñiga ${ }^{20}$, evidencia un marcado tono personal que encontró un adecuado armazón en la estructura barroca clasicista trazada por fray Pedro quien introdujo la valoración del sistema de los órdenes y del vocabulario clásico como protagonista de una movida composición de depuradas líneas. Si en el lema del escudo puede leerse parte del Salmo 25 -“OCVLI MEI SEM[PE]R AD DOMIN[U]M"- quienes accedían al interior de la colegiata no dejarían de fijar sus miradas en aquellos elementos que identificaban al responsable de finalizar el proyecto.

Cierto es que no resulta posible determinar la influencia de don Antonio en la elección del arquitecto ni en su propuesta, por otra parte, relacionada con la que el benedictino había llevado a cabo en Nuestra Señora del Prado de Valladolid, pero, desde luego, no estuvo al margen de la obra, según revelan el programa iconográfico o la impor-

\footnotetext{
${ }^{20}$ Zaparaín Yáñez, Desarrollo artístico... II, 383.
} 
tancia del escudo y la cartela en el diseño. Con todo ello, don Antonio ponía fin al dilatado proceso constructivo del templo, destacando su papel como digno heredero del título familiar, pero también como elocuente testimonio del respeto hacia el papel que sus predecesores habían desempeñado en el pasado, aunque con un sentido personalista en el cual parece intuirse una nueva dinámica.

Posteriormente, el conde, interesado en reformar sus residencias madrileñas para adaptarlas a los usos requeridos, centró su atención en la quinta de recreo que poseía en Carabanchel Alto. Se interesó, no tanto por intervenir en la estructura del edificio, organizada en torno a un torreón cuadrangular, sino por adecuar su envoltura natural, revelando una sensibilidad muy acorde a la importancia concedida, en las empresas regias, a los juegos de agua como membranas permeables con la que se relacionaba la arquitectura y sin las cuales no era posible su correcto entendimiento. Para ello invirtió medio millón de reales, “...dotándola de minas de agua, estanques y fuentes..."21. De este modo, la antigua residencia, de severa traza clasicista, se convirtió en una posesión de recreo bien valorada, en un momento en el que se puso de moda descansar en estas fincas de los alrededores de la corte para aliviar el rigor de los calurosos veranos madrileños ${ }^{22}$. Su sensibilidad hacia la naturaleza explica que, en 1748, alquilara un huerto a José Quer, quien organizó en él un jardín botánico que, por primera vez en Madrid, tenía un carácter público ${ }^{23}$. Su relación con tan

\footnotetext{
${ }^{21}$ Félix de Llanos y Torriglia, María Manuela Kirkpatrick, condesa de Montijo (Madrid: Espasa-Calpe, 1932), 106.

${ }^{22}$ Eva J. Rodríguez Romero, El jardín paisajista y las quintas de recreo de los Carabancheles: la posesión de Vista Alegre (Madrid: Fundación Universitaria Española, 2000), 88-92.

${ }^{23}$ Ricardo Pascual, El botánico José Quer (1695-1764): primer apologista de la ciencia española (Valencia: Instituto de Historia de la Medicina, 1970), 16; Francisco Javier Puerto Sarmiento, La ilusión quebrada. Botánica, sanidad y política científica en la España Ilustrada (Madrid: Consejo Superior de Investigaciones Científicas, 1988), 34.
}

prestigioso científico, pieza clave en la fundación del Real Jardín Botánico, en $1755^{24}$, debe enmarcarse en el contexto cultural y científico en el que don Antonio parecía estar inmerso a mediados de la centuria.

En esa línea, destaca su relación con relevantes arquitectos a través de su participación en la Junta de Hospitales de Madrid ${ }^{25}$, al ostentar el cargo de hermano mayor de los Reales Hospitales General y de la Pasión ${ }^{26}$. Sería en este entorno en el que conoció a Ventura Rodríguez ${ }^{27}$ y a José de Hermosilla a quien debió de encomendar la renovación de la capilla de las Reliquias en el convento de Domus Dei en La Aguilera ${ }^{28}$, que había sido edificada por el VI conde de Miranda para su enterramiento y el de su esposa a principios del siglo XVII ${ }^{29}$. No nos consta si el espacio se encontraba en mal estado, pero, sin duda, su riguroso clasicismo no encajaría con la exaltada concepción barroca del tem-

${ }^{24}$ Carmen Añón, Real Jardín Botánico de Madrid: sus orígenes, 1755-1781 (Madrid: Consejo Superior de Investigaciones Científicas, 1987).

${ }^{25}$ Juan Manuel Núñez Olarte, El Hospital General de Madrid en el siglo XVIII: actividad médico-quirúrgica (Madrid: Consejo Superior de Investigaciones Científicas, 1999) 47, 111.

${ }^{26}$ Constituciones y ordenanzas para el gobierno de los Reales Hospitales General y de la Passión de Madrid (Madrid: Antonio Marín, 1760).

${ }^{27}$ Francisco José León Tello y M. - Virginia Sanz Sanz, Estética y teoría de la arquitectura en los tratados españoles del siglo XVIII (Madrid: Consejo Superior de Investigaciones Científicas, 1994), 448.

${ }^{28}$ Zaparaín Yáñez, Desarrollo artístico... II, 483-485; Delfín Rodríguez Ruiz, "José de Hermosilla. Arquitecto", en José de Hermosilla y Sandoval (Badajoz: Diputación Provincial de Badajoz, 2015), 32.

29 Zaparaín Yáñez, Desarrollo artístico... II, 328-331; M. a José Zaparaín Yáñez y Juan Escorial Esgueva, “María de Zúñiga y Avellaneda, VI condesa de Miranda. Linaje, promoción artística y devoción en los umbrales del Barroco", en El Barroco: universo de experiencias, coord. por $\mathrm{M}^{\mathrm{a}}$ del Amor Rodríguez Miranda y José Antonio Peinado Guzmán (Córdoba: Hurtado Izquierdo, 2017), 209. 
plo conventual, erigido tras la beatificación de fray Pedro Regalado ${ }^{30}$.

Sin embargo, esto no parece suficiente excusa como para decidirse a intervenir en un ámbito diseñado por uno de sus antepasados más ilustres, salvo si quiso enlazar su memoria con la de aquel. El trabajo consistió en redefinir el interior del espacio, cubierto por una bóveda semiesférica sobre alto tambor animada con una pintura sobre la Gloria, hoy desaparecida ${ }^{31}$, y completarlo con un cuidado retablo relicario que, efectuado en 1755 bajo proyecto de Hermosilla, cubrió tres lienzos de la capilla (Fig. 3) ${ }^{32}$. Así, la estricta geometría del Clasicismo de 1600 se actualizaba sin concesiones al barroquismo del resto del edificio, lo cual permitía seguir manteniendo la dualidad de los diferentes ámbitos del santuario, según lo había querido el VI conde de Miranda ${ }^{33}$.

De este modo, las intervenciones en Peñaranda de Duero y La Aguilera le permitieron a don Antonio recuperar el sentido de linaje de las promociones familiares, perdido hacía décadas, dejando un legado renovado con el que podría encontrarse más identificada la nueva generación que sería la encargada de culminar alguna de las propuestas. No obstante, esta transición fue especialmente difícil para el conde, pues, a principios de 1762, fallecía su primogénito, Rafael, viéndose obligado a solucionar el problema sucesorio, concertando el matrimonio de su segundo hijo, Pedro de Alcántara, con su so-

\footnotetext{
${ }^{30}$ José Miguel Muñoz Jiménez, “Barroco y peregrinación: el santuario de San Pedro Regalado en La Aguilera", Goya: revista de arte, no 228 (1992), 330-336; Zaparaín Yáñez, Desarrollo artístico... II, 384-395.

${ }^{31}$ Luis Carrión González, Historia documentada del convento Domus Dei de La Aguilera (Madrid: Prensa Ibérica, 1930), 221.

32 Zaparaín Yáñez, Desarrollo artístico... II, 483-485; René J. Payo Hernanz, “De los esplendores barrocos a las luces de la razón: retablos y esculturas del siglo XVIII en la Ribera del Duero", Biblioteca: estudio e investigación, $\mathrm{n}^{\circ} 20$ (2005), 280-281.
}

${ }_{33}$ Zaparaín Yáñez y Escorial Esgueva, “María de Zúñiga...", 209.

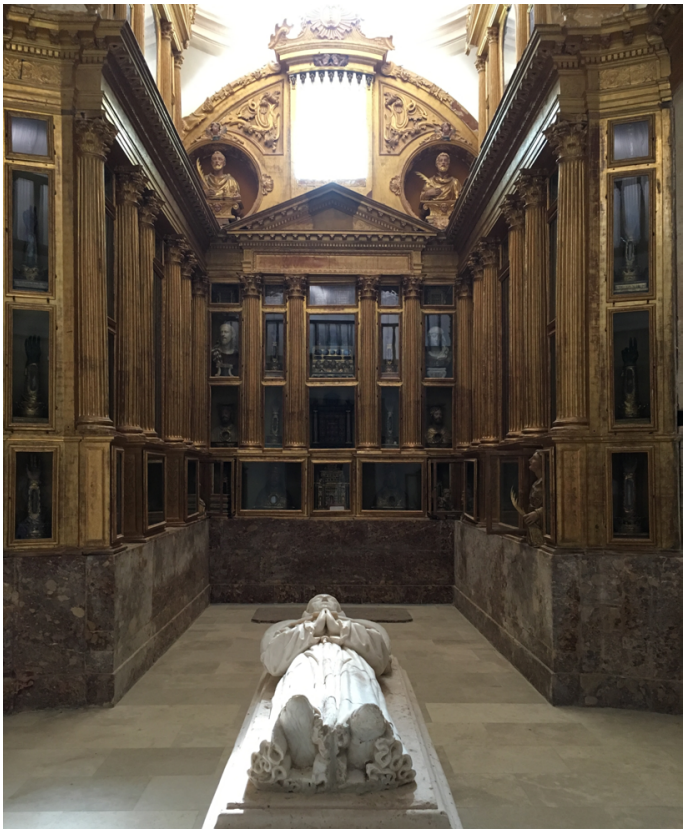

- Fig. 3. Capilla de la Gloria del convento de Domus Dei de La Aguilera (Burgos). Fotografía de los autores.

brina, Ana María Velasco Téllez Girón, hija del duque de Frías, quienes se casaron al año siguiente $^{34}$. Entonces, el XIII conde estaba ya muy enfermo, al haber sufrido "un ataque" que le privó del habla, falleciendo en agosto de $1765^{35}$.

\section{UNA NUEVA IMAGEN PARA UN NUEVO TIEMPO (1765-1790)}

Pedro de Alcántara López de Zúñiga (1731-1790), XIV conde de Miranda, siguió explorando las vías iniciadas por su padre, con un claro deseo de continuación, como evidencia el mantenimiento de la apuesta cortesana y académica, la cual dio singulares frutos que contribuyeron a imponer la imagen de un noble al servicio de la Corona, moderno, culto e interesado por las artes, en la línea de comportamiento de otros prestigiosos miembros de la nobleza ${ }^{36}$.

\footnotetext{
${ }^{34}$ Paula de Demerson, María Francisca de Sales Portocarrero (condesa de Montijo). Una figura de la Ilustración (Madrid: Editora Nacional, 1975), 33.

${ }^{35}$ Demerson, María Francisca..., 33.

${ }^{36}$ Este es el caso, por ejemplo, de José Antonio Vigara Zafra, "El palacio del VI conde de Fernán Núñez.
} 


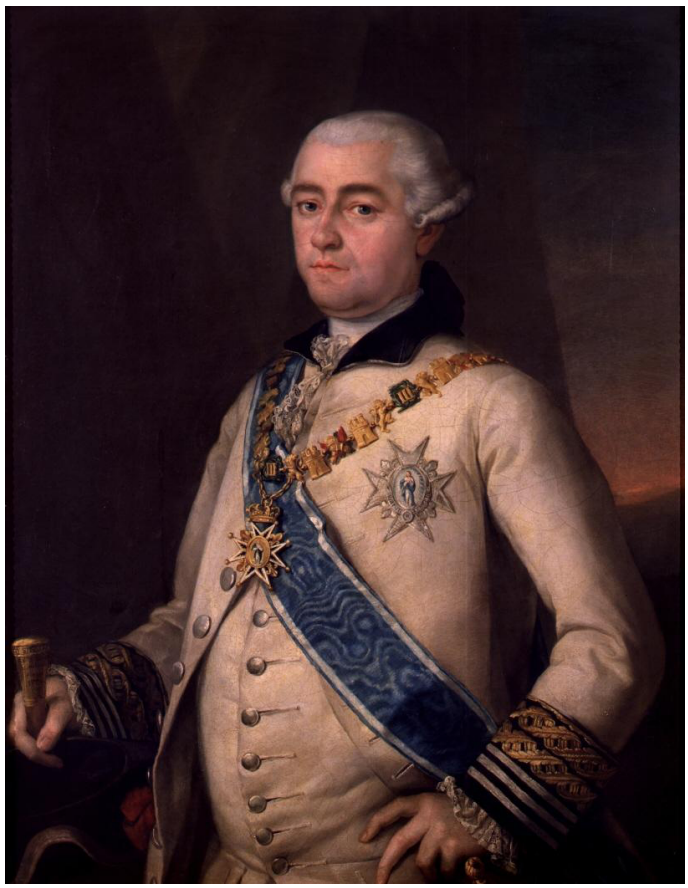

- Fig. 4. Francisco Bayeu (atribuido). Retrato de Pedro de Alcántara López de Zúñiga, XIV conde de Miranda. 1774. (C) Museo Lázaro Galdiano, $\mathrm{n}^{\mathrm{o}} 1993$.

No hay mejor ejemplo de ello que el elegante retrato conservado en el Museo Lázaro Galdiano, fechado en 1774 y atribuido, según los estudios más recientes, a Francisco Bayeu (Fig. 4$)^{37}$. Representa al conde, en una elaborada puesta en escena, como teniente general y caballero de la Gran Cruz de la Real Orden de Carlos III, que obtuvo el mismo año de su creación -1771-, en recompensa a sus servicios. Aparte de las insignias correspondientes, porta el collar, máxima distinción otorgada a quienes llevaban más de tres años ostentando la Gran Cruz. Dada la fecha del lienzo, acabaría de recibirlo y de ahí que la obra pudiera haber tenido la finalidad de exhibir su nueva condición, siguiendo la costumbre de la nobleza de potenciar en los retratos la importancia de las condecoraciones concedidas, como distinción social, en un tiempo en el cual no solo ellos tenían acce-

La arquitectura como exaltación simbólica del linaje durante la Ilustración", Tiempos Modernos 8, no 29 (2014).

${ }^{37}$ Arturo Ansón Navarro, Los Bayeu, una familia de artistas de la Ilustración (Zaragoza: Caja Inmaculada, 2012), 74. Anteriormente fue atribuido a Goya. so a este recurso visual ${ }^{38}$ y que, a su vez, era un signo de afirmación individual frente a la importancia del linaje familiar que resultaba claramente diluida.

Entre sus actuaciones, al igual que su padre, se preocupó de las propiedades madrileñas y, en 1774, hizo ver a la ciudad que la pavimentación llevada a cabo en la plaza de las Carboneras había provocado un significativo incremento de nivel y dificultaba el tránsito de los carruajes, desplazando el agua de lluvia hacia los bajos de su residencia. Don Pedro logró que el Concejo autorizase el rebaje de la plaza según la propuesta de José de la Ballina ${ }^{39}$. Tampoco se olvidó de la Quinta de Carabanchel en la que, en 1786, efectuó plantaciones para mejorar la finca, haciéndola más fresca y amable ${ }^{40}$, en un momento en el que el interés por los jardines y las nuevas plantaciones en la corte estaban de plena actualidad. De ello queda un elocuente testimonio en una delicada acuarela de Juan Mieg, la cual formaba parte del conjunto de vistas que el afamado naturalista suizo realizó de los alrededores de Madrid (Fig. 5).

Sin embargo, fue en la colegiata de Peñaranda de Duero, de tanta significación para su padre, donde dejó su promoción más definitoria, al apoyar, en 1782, la renovación del amueblamiento de la cabecera ${ }^{41}$.

38 Álvaro Molina, Mujeres y hombres de la España ilustrada. Identidad, género y visualidad (Madrid: Cátedra, 2013), 176-181.

${ }^{39}$ AVM, 1-47-48.

${ }^{40}$ Archivo Histórico Nacional (AHN), Estado, leg. 3473, caja 2, doc. 82 .

${ }^{41}$ Inocencio Cadiñanos Bardeci, "Actuación de Ventura Rodríguez en la provincia de Burgos", Archivo Español de Arte, vol. LIX, no 233 (1986), 53-68; “El arquitecto Manuel Martín Rodríguez, discípulo de Ventura Rodríguez", Academia: Boletín de la Real Academia de Bellas Artes de San Fernando, 71 (1990), 411-480; Alberto C. Ibáñez Pérez, “La introducción del Neoclasicismo en Burgos: retablos y escultura", Academia: Boletín de la Real Academia de Bellas Artes de San Fernando, 69 (1989), 63-90; Zaparaín Yáñez, Desarrollo artístico... II, 479-482; “De la herencia barroca a la racionalización de la vivencia espiritual: las fábricas religiosas", Biblioteca: estudio e in- 


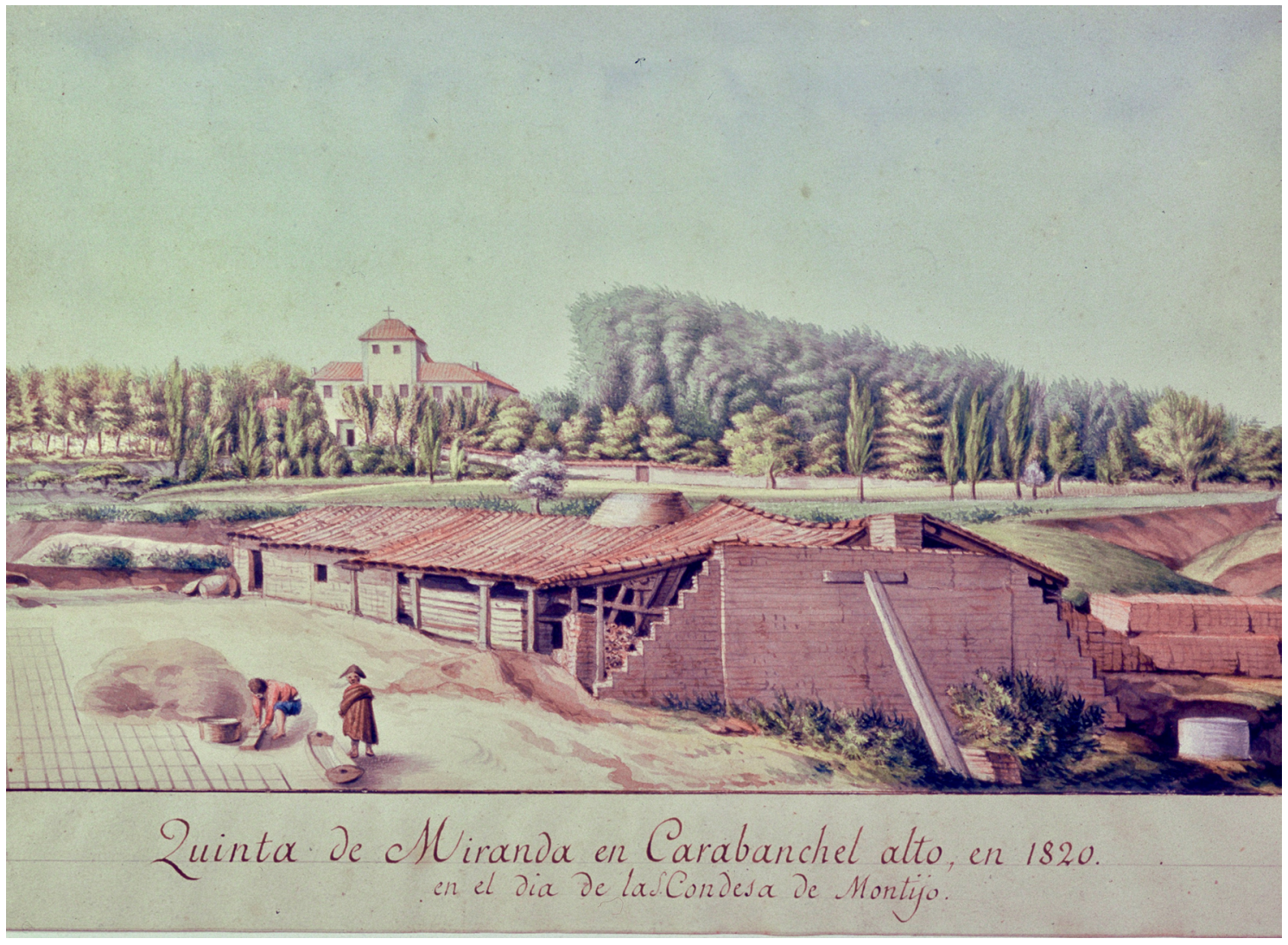

- Fig. 5. Juan Mieg. Vista de la Quinta de Miranda, en Carabanchel (1820). Colección particular

El conde supo transmitir, a través de su implicación personal, el carácter cortesano del entorno en el que se encontraba inmerso. De este modo, tomó las riendas de la empresa, dirigiéndose al antiguo director de la Academia de San Fernando, Ventura Rodríguez, a quien habría conocido a través de los contactos de su progenitor.

El arquitecto definió las características de la nueva obra según los gustos del momento y, en función de ellas, la personalidad de quienes intervinieron, así como los procedimientos seguidos para que todo se llevara a cabo según lo establecido. Al depositar el conde su confianza en él, se guió de su formado criterio y de su exitosa experiencia en las piezas de amueblamiento como avalan,

vestigación, 20 (2005), 281-282; Payo Hernanz, “De los esplendores...", 337-338; René J. Payo Hernanz y José Matesanz del Barrio, "La presencia del maestro arquitecto fray José de San Juan de la Cruz en Castilla", en Fray José de San Juan de la Cruz y el arte rococó en La Rioja (Logroño: Instituto de Estudios Riojanos, 2018), 159-162. entre otras, el transparente de la catedral de Cuenca, el tabernáculo para la iglesia del monasterio de la Encarnación de Madrid o los retablos mayores de la catedral de Zamora y del santuario de Arenas de San Pedro ${ }^{42}$, con las que el retablo de Peñaranda de Duero guardará relación.

Desde esta dinámica, don Ventura se rigió por los principios académicos en los que la idea triunfaba sobre la ejecución material, traduciendo aquella a través de un diseño, al que los profesionales encargados de su realización se remitirán de forma constante durante el trabajo ${ }^{43}$. Aquel había sido firmado por el arquitecto en Madrid el 10 de julio de 1783, contando con la aprobación del conde $^{44}$. Después, se envió a Peñaranda de

\footnotetext{
${ }^{42}$ M. ․ Teresa Cruz Yábar, “Los retablos de Ventura Rodríguez", en Ventura Rodríguez, arquitecto de la Ilustración (Madrid: Comunidad de Madrid, 2018), 169-206.

${ }^{43}$ Zaparaín Yáñez, Desarrollo artístico... II, 479-482.

${ }^{44}$ Archivo Histórico Provincial de Burgo (AHPBu),
} 
Duero con el fin de que lo conociera el Cabildo y quedara depositado en la contaduría de la colegiata "...para el gobierno y dirección..." de la obra ${ }^{45}$.

La traza diseñada por Ventura Rodríguez desaparecería en alguna de las habituales consultas, pero debe corresponderse con un dibujo que apareció recientemente en Christie's (Fig. 6) ${ }^{46}$, si bien se encuentra recortada en su parte inferior, careciendo de la firma identificativa referida en la documentación ${ }^{47}$. En ella queda recogida la estructura general del retablo, de dos cuerpos de proporción dupla, de orden corintio, describiendo con precisión sus detalles decorativos, entre los que destacan "...dos acróteras con sus luminarias..." 48 , ya planteadas en el retablo mayor de la catedral de Zamora.

Pero también se fijó el programa escultórico organizado en torno a un relieve central, dedicado a la titular; mientras, el ático quedaba presidido por un Calvario y, el frontón superior, coronado por un medallón con la figura de Dios Padre. Asimismo, se dejaba establecido el protagonismo compositivo y simbólico concedido al sagrario expositor que simplifica el efectuado por don Ventura para la Encarnación de Madrid ${ }^{49}$, convirtiéndolo en el foco visual del retablo. Su estudiada ejecución le permitió adaptar, desde los presupuestos académicos de triunfo del orden, el sentido eucarístico de las máquinas retablísticas barrocas, y actualizar la antigua

Prot. 5321/1, ff. 459-460v.

${ }^{45}$ AHPBu, Prot. 5321/1, ff. 459-460v, 490-490v.

${ }^{46}$ Fue subastado en Londres el 7 de diciembre de 2016 (Subasta 13322, lote 45). Fue puesto en relación con la obra peñarandina por el profesor Benito Navarrete en el catálogo de la subasta, a quien agradecemos su generosa atención en lo relativo a esta cuestión. Reproducido en Javier Ortega Vidal, José Luis Sancho Gaspar y Francisco Javier Marín Perellón, Ventura Rodríguez. El poder del dibujo (Madrid: Comunidad de Madrid, 2018), 512.

${ }^{47}$ AHPBu, Prot. 5321/1, ff. 459-460v.

${ }^{48}$ ADBu, Peñaranda de Duero, Leg. 40. Condiziones para la obra del altar mayor.

${ }^{49}$ Cruz Yábar, “Los retablos...”, 190-191.

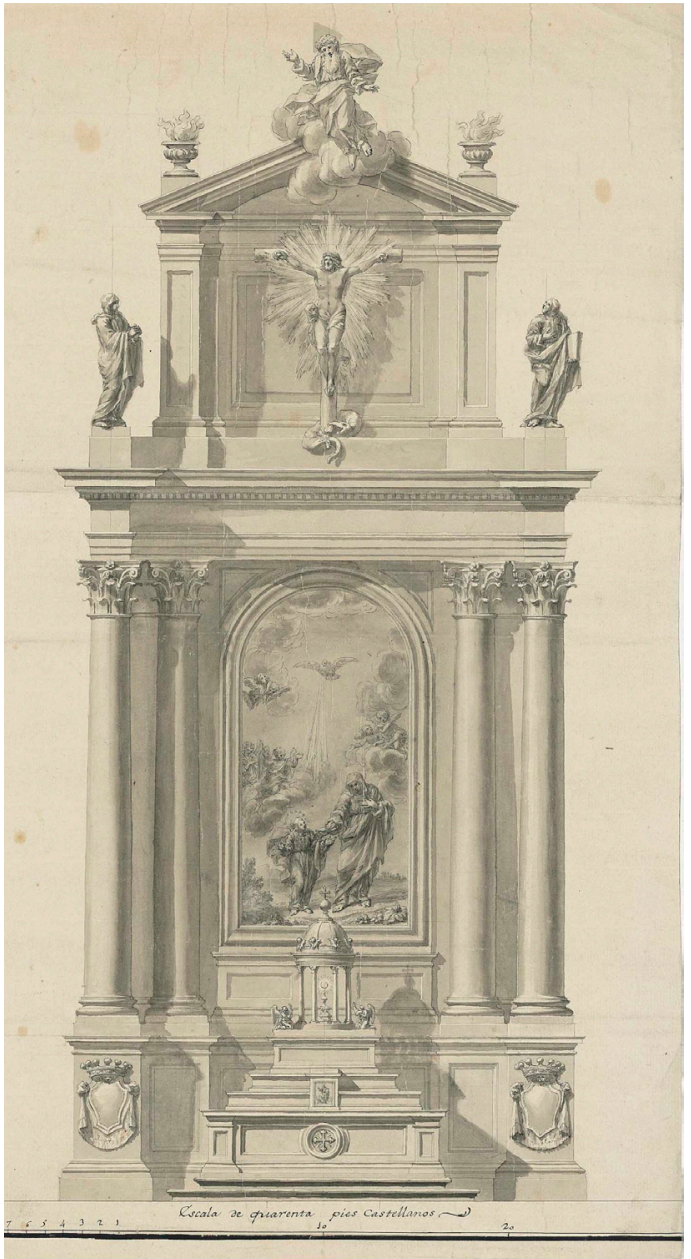

- Fig. 6. Ventura Rodríguez. Traza del retablo mayor de Peñaranda de Duero (1783). Colección particular. Reproducida en Javier Ortega Vida, José Luis Sancho Gaspar y Francisco Javier Marín Perellón, Ventura Rodríguez. El poder del dibujo (Madrid: Comunidad de Madrid, 2018), 512.

devoción familiar de los condes de Miranda hacia el Santísimo Sacramento.

En el diseño se buscó ofrecer una imagen próxima al efecto que produciría la obra, algo que, en otras ocasiones, le llevó a Ventura Rodríguez, incluso, a preparar una maqueta $^{50}$. Para ello, siguiendo las características del diseño académico, se prestó especial cuidado a las sombras, como necesario complemento de una arquitectura de elementos

\footnotetext{
${ }^{50}$ Juan Nicolau Castro, "Modelo de Ventura Rodríguez para el transparente de la Catedral de Cuenca", Academia. Boletín de la Real Academia de Bellas Artes de San Fernando, no 91 (2000), 51-54.
} 
depurados a los que confería plasticidad y monumentalidad, mientras le restaba rigidez y frialdad. Se conseguía, entonces, un equilibrado efectismo en el cual armonizaba la severidad de una propuesta de esta naturaleza con la imprescindible inmediatez de un diseño que debía seducir tanto a don Pedro como al Cabildo de la colegiata. De este modo, ninguna de las partes implicadas tendría duda de cuál sería el aspecto de la obra una vez terminada.

Sin embargo, Ventura Rodríguez no se limitó a realizar el diseño gráfico, sino que dirigió la empresa en todos sus pormenores, sin olvidar la "...regulación de su coste, los precios de las maderas y salarios de los oficiales, como todas las demás cosas concernientes asta su colocación..."51. El conjunto, además, incluía intervenciones de diferente signo -arquitectura, escultura, dorado y jaspeado-, imponiendo el arquitecto sus criterios sobre las restantes artes, pues de ellas dependía, a su vez, que su planteamiento presentase los rasgos con los que fue concebido. Esto obligaba a que la realización material se encomendase a especialistas de cada una de las artes implicadas cuya contratación no podía, por tanto, quedar al azar del siempre imprevisible sistema de subastas ${ }^{52}$.

Este, con sus arriesgadas bajas, era el procedimiento tradicional y don Ventura, como la Academia, desconfiaba del mismo. En relación con ello, los artífices serían conocidos del arquitecto o de Manuel Martín Rodríguez, quien se hizo cargo del proyecto, bajo los mismos presupuestos, a la muerte de su mentor ${ }^{53}$. De ahí que se dirigieran al contexto académico o al vallisoletano, bien controlado por don Ventura ${ }^{54}$. De la capital

${ }^{51} \mathrm{ADBu}$, Peñaranda de Duero, Libro de Decretos (1775-1788), 10/09/1783, ff. 124-124v.

${ }^{52}$ AHPBu, Prot. 5321/1, ff. 459-460v.

${ }^{53}$ Cadiñanos Bardeci, “El arquitecto...”.

${ }^{54}$ María José Redondo Cantera, “La situación profesional de la arquitectura y los arquitectos en Valladolid durante el reinado de Carlos III", en 1992. El arte español en épocas de transición. Actas del IX Congreso Nacional de Historia del Arte (León: Universidad de León, 1992), 53-62. castellana procedían Pablo Álbaro, a quien aquel recomendó para la realización de la estructura arquitectónica, y los pintores y doradores Miguel García y Ramón y Joaquín Canedo $^{55}$, mientras que la escultura corrió a cargo del teniente director de Escultura de San Fernando, Alfonso Giraldo Bergaz ${ }^{56}$. Por su parte, el conde estuvo al día de todos los pormenores de la empresa, según pone de manifiesto la fluida correspondencia que mantuvo con el Cabildo de la colegiata, actuando como coordinador de las diferentes partes implicadas, pidiendo, incluso, que este enviara un representante a Madrid, ante la lentitud derivada de la necesidad de consultar de forma epistolar todos los aspectos relacionados con el retablo mayor ${ }^{57}$.

Poco después, el Cabildo siguió avanzando en un proyecto que ganaba en ambición, decidiendo, a mediados de octubre de 1785, encargar a Pablo Álbaro la ejecución de dos colaterales en los que situar la colección de relicarios del templo colegial ${ }^{58}$. En su diseño se tuvo en cuenta “...el altar maior, para que guarde uniformidad con este que parezca todo de una mano..." 59 , como consta en un rasguño, seguramente realizado por Álbaro, conservado en el Archivo Diocesano de Burgos (Fig. 7) ${ }^{60}$. Sin embargo, se abandonó esta idea, optando por un depurado diseño arquitrabado en el que, a través de sendas puertas acristaladas, podían apreciarse

55 Joaquín Canedo fue alumno de la Academia entre 1775 y 1784: Archivo de la Real Academia de Bellas Artes de San Fernando (ARABASF), Actas, 1775, 5 de noviembre, ff. 346-346v; 1776, 4 de febrero, f. 11; 1778, 11 de julio, ff. 85v-86; 1779, 2 de mayo, ff. 127-127v, etc.

${ }^{56}$ Zaparaín Yáñez, Desarrollo artístico... II, 479-482.

57 ADBu, Peñaranda de Duero, Libro de Decretos (1775-1788), f. 124.

${ }^{58}$ ADBu, Peñaranda de Duero, Libro de Decretos (1775-1788), 08/10/1785, ff. 150-151; Leg. 40. Recibo del primer tercio del pago de los colaterales (24/11/1785).

${ }^{59} \mathrm{ADBu}$, Peñaranda de Duero, Leg. 40. Razones del coste forma de architectura y medidas que an de tener dos altares en donde se an de colocar setenta reliquias.

${ }^{60} \mathrm{ADBu}$, Peñaranda de Duero, Leg. 40. Documentación varia. 


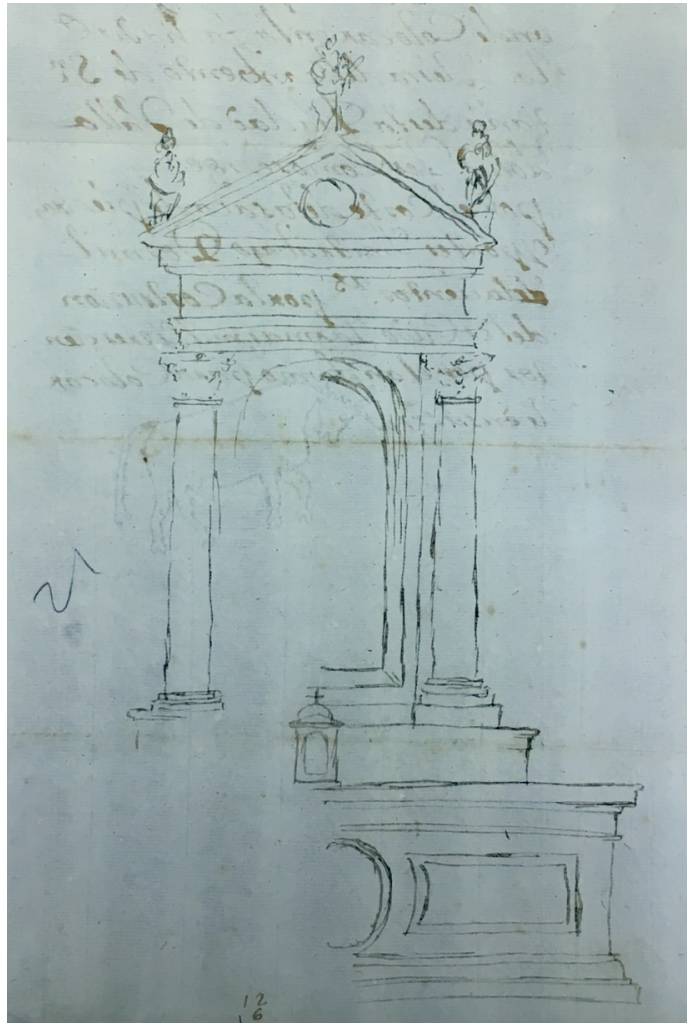

- Fig. 7. Pablo Álbaro (atribuido). Rasguño para los retablos colaterales de la colegiata de Peñaranda de Duero (h. 1785). Archivo Diocesano de Burgos, Peñaranda de Duero, Leg. 40, documentación varia.

los bellos relicarios, manteniendo su correspondencia con el retablo mayor a través de su estructura clasicista y del marmoleado de sus superficies. La realización de estas piezas culminó las obras del templo de Peñaranda de Duero y sirvieron de adecuado epílogo a las aportaciones de los condes de Miranda a la fundación de sus predecesores, actualizando un rico legado desde los presupuestos cortesanos y académicos del último cuarto del setecientos.

En esta dinámica, de claro corte ilustrado, siguió desenvolviéndose y así lo revela su amistad con el conde de Aranda, al que eligió como uno de sus testamentarios ${ }^{61}$, o las gestiones realizadas para lograr el enlace matrimonial de su heredera, María del Carmen Josefa, con Pedro de Alcántara Álvarez

\footnotetext{
${ }^{61}$ AHPM, Prot. 24.835, ff. 469 y ss.
}

de Toledo, hijo menor de los $\mathrm{X}$ marqueses de Villafranca, en $1790^{62}$.

\section{EL FIN DE UN LINAJE (1790-1830)}

No cabe duda de que el matrimonio de su hija colmaría de satisfacción a don Pedro al entroncar con una de las familias de mayor prestigio en la corte y que, a su vez, poseía un destacado papel en el mundo de las artes. Su esposo, Pedro de Alcántara Álvarez de Toledo (1765-1824), tras la temprana muerte de su padre, tuvo como referente a su hermano mayor, José Álvarez de Toledo -XV duque de Medina Sidonia-, casado con María del Pilar Teresa Cayetana de Silva y Álvarez de Toledo -XIII duquesa de Alba-, quienes desarrollaron una importante actividad artística y cultural ${ }^{63}$. Con su hermano compartió inquietudes y afanes, fue su guía en los círculos cortesanos y en él confió durante los tensos momentos vividos con motivo de la conspiración de Alejandro Malaspina, en 1795, quien, tras su expedición, intentó que don José ocupara el puesto de Manuel Godoy. El plan fracasó y el duque se retiró a sus estados donde falleció un año después, lo cual afectó profundamente al conde de Miranda ${ }^{64}$. Pero Godoy no olvidó la afrenta y así lo demuestra una carta que escribió a la reina María Luisa manifestando su desconfianza hacia su viuda, la duquesa de Alba, y sus cuñados, los Miranda, proponiendo "...destinarlos a diferentes empleos en distancias, así agradecerán, o, por lo menos, no murmurarán..."65.

Sin embargo, don Pedro, al igual que su padre y su hermano, desarrollaría su vida en la corte al servicio de la Corona, donde fue Gentil Hombre de Cámara y alcanzó relevantes dignidades y condecoraciones como el hábito de caballero de la Orden de Santia-

\footnotetext{
${ }^{62}$ AHN, Consejos, 9816, A. 1790, exp. 1.

${ }^{63}$ Manuela B. Mena Marqués y Gudrun Maurer, La duquesa de Alba, "musa" de Goya: el mito y la historia (Madrid: El Viso, 2006), 89.
}

\footnotetext{
${ }^{64}$ Mena Marqués y Maurer, La duquesa..., 191-194.

${ }^{65}$ Mena Marqués y Maurer, La duquesa..., 214.
} 
go y la Gran Cruz de la Orden de Carlos III ${ }^{66}$. También, a través del ejemplo de José Álvarez de Toledo, se familiarizó con el mundo académico y el trato con los principales artistas del momento, mostrando aprecio hacia la obra de Agustín Esteve. Prueba de ello es la importancia concedida al retrato, lo cual, unido a los estrechos vínculos que mantuvo con su familia, le llevó a encargarle a este la copia de dos retratos de don José y de la duquesa de Alba realizados por Goya ${ }^{67}$. Esta circunstancia, además de la valoración artística de las obras, les permitiría mostrarse como integrantes de uno de los círculos nobiliarios más significativos del momento.

A su vez, la documentación relativa a las últimas voluntades de su madre, la marquesa de Villafranca, alude a que era práctica habitual en la familia intercambiar los retratos con el fin de tener siempre presente la imagen de sus seres queridos y exhibir las alianzas de poder entretejidas a lo largo del tiempo entre los principales linajes ${ }^{68}$. Esta costumbre habla, también, de la movilidad que estaban adquiriendo las obras pictóricas dentro de una nueva concepción de las mismas, donde su valoración artística cobraba cada vez mayor importancia ${ }^{69}$. En ese contexto debe situarse el retrato de la condesa, atribuido a Esteve ${ }^{70}$ y conocido a través de una antigua fotografía (Fig. 8) que puede relacionarse con los retratos que el artista

${ }^{66} \mathrm{AHN}$, Órdenes Militares, Expedientillos, no ${ }^{\circ}$ 18405; Estado-Carlos III, exp. 905.

${ }^{67}$ El primero, custodiado en el Art Institute de Chicago, representa al duque sentado, mientras el segundo debe corresponder al de la duquesa vestida de blanco del palacio de Liria. Mena Marqués y Maurer, La duquesa...89, 93, 111 .

${ }^{68}$ Mena Marqués y Maurer, La duquesa..., 217-218.

${ }^{69}$ Urquízar Herrera y Vigara Zafra, "La nobleza...", 269-270; Antonio Urquízar Herrera, "Las obras de arte en la supresión de los mayorazgos: el debate parlamentario y el pleito por la testamentaría de la XIII duquesa de Alba (1802-1844)", Boletín de Arte, nº 37 (2016), 203211.

${ }^{70}$ Martín S. Soria, Agustín Esteve y Goya (Valencia: Institución Alfonso El Magnánimo y Diputación Provincial de Valencia, 1957), 65 y 118.

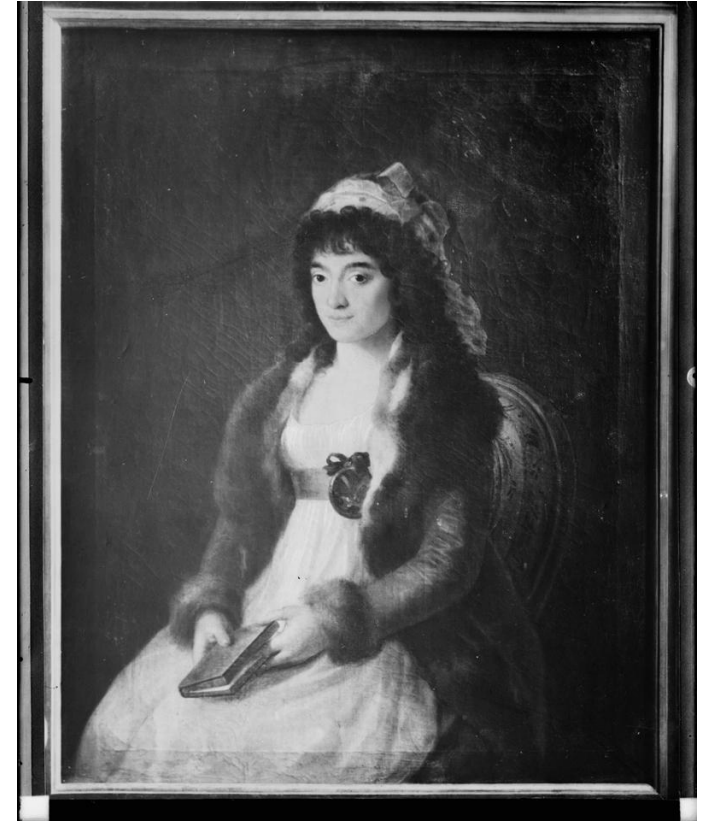

- Fig. 8. Agustín Esteve. Retrato de María del Carmen Josefa López de Zúñiga, XV condesa de Miranda (h. 1805). Fototeca del Instituto de Patrimonio Histórico, Moreno, 2481C (Subdirección General de Coordinación Bibliotecaria, Ministerio de Cultura. Licencia Creative Commons)

valenciano pintó en la corte a principios del siglo XIX. Vistiendo a la moda del momento, doña María del Carmen Josefa responde al concepto de refinamiento femenino impuesto a partir de la segunda mitad del setecientos $^{71}$.

En línea con lo anterior, el propio conde, consciente del valor del retrato como elemento de memoria, hizo entrega, en 1798, de treinta estampas con el retrato de su hermano, el duque de Alba -fallecido dos años antes-, grabadas por Salvador Carmona en base al lienzo de Goya, hoy conservado en Chicago (Fig. 9) ${ }^{72}$, como la mejor forma de honrar a quien tanta importancia había concedido al grabado ${ }^{73}$. Precisamente, este de-

${ }^{71}$ Virginia Albarrán. “Goya y el refinamiento femenino en el siglo XVIII" en Goya y la corte ilustrada (Madrid: Museo Nacional Del Prado, Museo de Bellas Artes de Bilbao y Obra Social La Caixa, 2017), 128-163.

${ }^{72}$ ARABASF, Actas, 1798, 6 de mayo, f. 98.

${ }^{73}$ Urquízar Herrera y Vigara Zafra, "La nobleza...", 264 


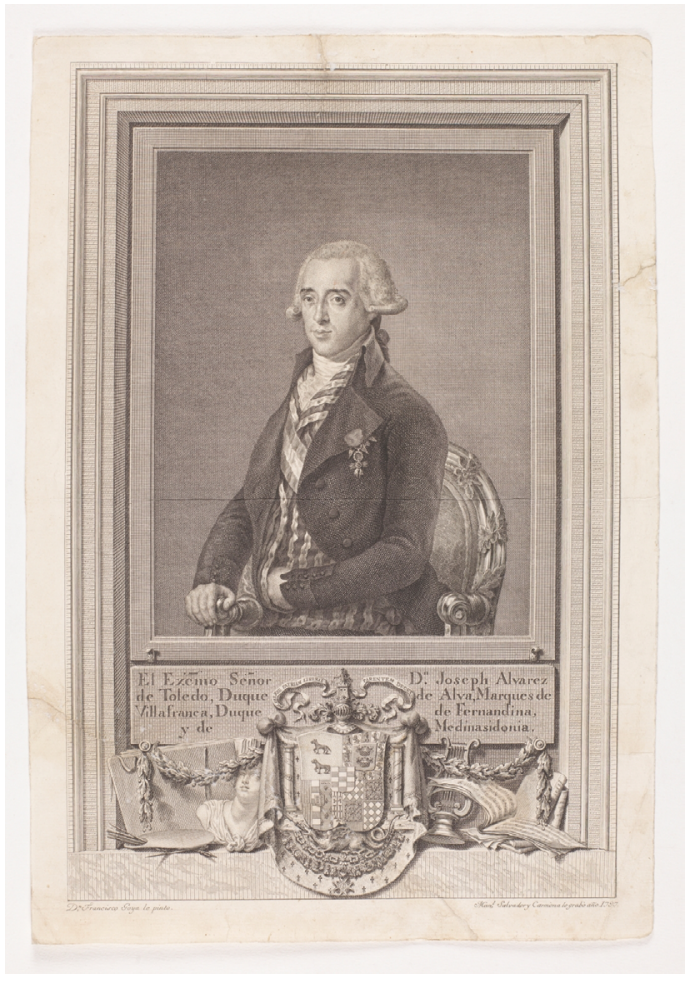

- Fig. 9. Manuel Salvador Carmona. Retrato de José Álvarez de Toledo, duque de Alba, según Francisco de Goya (1797). Museo Nacional del Prado, G2561.

talle le valió ser propuesto como académico de honor, en junio de ese mismo año, “...en atención a las distinguidas circunstancias que concurren en la persona de S.E. y a su afición a las nobles artes..."74, dentro de una dinámica habitual en la institución, y pasando a formar parte del selecto grupo de nobles que tenía presencia en la misma ${ }^{75}$.

Sin descuidar los intereses de los Zúñiga, a los que ahora representaba tras su matrimonio $^{76}$, dedicó gran parte de sus ocu-

\footnotetext{
${ }^{74}$ ARABASF, Actas, 1798, 3 de junio, f. 99; 1 de julio,

${ }^{75}$ Claude Bédat, La Real Academia de Bellas Artes de San Fernando (1744-1808) (Madrid: Fundación Universitaria Española, 1989); Urquízar Herrera y Vigara Zafra, "La nobleza...", 263.

${ }^{76}$ Fruto de este interés es la programación de un viaje a Peñaranda de Duero, en 1797, o el enconado pleito que mantuvo con el ducado de Frías para defender los derechos de su esposa al mayorazgo fundado por la III condesa de Miranda en favor de Gutierre de Cardenas. ADBu, Peñaranda de Duero, Libro de Decretos
} f. $107 \mathrm{v}$. paciones a la dirección de la Asociación del Buen Pastor, instituida en 1799 para atender a los presos pobres de las cárceles madrileñas ${ }^{77}$ a imitación de la que las damas tenían para las presas ${ }^{78}$. Según sus constituciones, aprobadas por Real Orden de 23 de julio de ese año, el ejercicio de la caridad cristiana se unía a las preocupaciones ilustradas por sus condiciones de vida, mejorando la salubridad de las cárceles, su alimentación y vestido, así como su instrucción. Fruto también de esta dinámica fue la traducción de la Noticia del estado de las cárceles de Filadelfia, editada en 1801 y dedicada al conde, donde, al dar a conocer los cambios experimentados en las instituciones americanas, se valoraban positivamente los llevados a cabo en las madrileñas bajo el impulso de las dos asociaciones ${ }^{79}$. Por su parte, la condesa también participó de las iniciativas ilustradas, siguiendo los pasos de la IX duquesa de Osuna, presidenta de la Junta de Damas de Honor y Mérito de la Real Sociedad Económica Matritense de Amigos del País, de la que fue censora, mientras su suegra ocupaba el cargo de vicepresidenta $^{80}$.

Estos compases previos a la Guerra de la Independencia vuelven a situar a don Pedro en abierta hostilidad contra Godoy, la cual le llevó, junto con otros miembros de importantes linajes, a ser desterrado de Madrid en septiembre de $1805^{81} \mathrm{y}$, dos años más tarde, en octubre de 1807, estaba inmerso en una nueva conspiración para conseguir que Carlos IV renunciara al trono en favor

(1788-1816), 05/05/1797, f. 141 y AHN, Consejos, 32923.

${ }^{77}$ Constituciones de la Real Asociación de Caridad establecida para alivio de los pobres presos en las cárceles de Madrid, con la advocación del Buen Pastor (Madrid: Imprenta de la Viuda de Ibarra, 1799).

\footnotetext{
${ }^{78}$ Demerson, María Francisca..., 175.

${ }^{79}$ Noticia del estado de las cárceles de Filadelfia (Madrid:
} Imprenta Real, 1801).

${ }^{80}$ Paloma Fernández Quintanilla, La IX duquesa de Osuna. Una ilustrada en la corte de Carlos III (Madrid: Doce Calles, 2017), 325.

${ }^{81}$ Emilio La Parra, Manuel Godoy. La aventura del poder (Barcelona: Tabula Tusquets, 2002), 355. 
de su heredero ${ }^{82}$. A pesar de que el príncipe de Asturias les delató, el conde le acompañó cuando marchó de España y le sirvió con "acendrada" fidelidad, experimentando "...muchos trabajos y tribulaciones de toda especie...", según avala el que le fuera concedida, el 23 de agosto de $1814^{83}$, la Gran Cruz de Lealtad en Valençay, creada por el monarca ese mismo día para distinguir al reducido número de cortesanos que cumplían estos requisitos ${ }^{84}$.

Todo ello le convirtió en uno de los hombres de confianza del soberano quien, a su regreso, le pone al frente del Real Hospicio de la Corte y de San Fernando, en un cargo que enlazaría con sus antiguas preocupaciones por los presos ${ }^{85}$. De especial relieve fue su nombramiento, el 7 de octubre de 1815 , como mayordomo mayor ${ }^{86}$ que se vio acompañado, el 17 de noviembre, con el de consiliario de la Real Academia de Bellas Artes de San Fernando ${ }^{87}$. Al año siguiente, alcanzó la distinción de la Orden del Toisón ${ }^{88}$, mientras la condesa era nombrada dama de la Real Orden de Damas Nobles de la reina María Luisa en $1817^{89}$.

El monarca, entre otras ocupaciones, recurrió al conde para que, en marzo de 1816, acudiese a Cádiz a recoger a su futura esposa y sobrina, la infanta portuguesa Isabel de Braganza, y a la hermana de esta, doña Francisca, quien iba a contraer matrimonio con el infante Carlos María Isidro, hermano de Fernando VII, celebrándose los dobles esponsales por poderes en los que el conde represen-

${ }^{82}$ Fernández Quintanilla, La IX duquesa..., 397.

83 Archivo General de Palacio (AGP), REI, RF7, $344 / 19$

${ }^{84}$ Gazeta de Madrid, 30 de agosto de 1814.

${ }^{85}$ Gazeta de Madrid, 15 de septiembre de 1814.

${ }^{86}$ María del Carmen López Sánchez, La mano del rey: el mayordomo mayor en la Casa Real del siglo XIX, (Madrid: Universidad Carlos III de Madrid, 2017), 108-110.

${ }^{87}$ ARABASF, Exp. 1-39-3.

${ }^{88}$ AHN, Estado, 7686, exp. 23.

${ }^{89}$ AHN, Estado 7562, exp. 21; 7569, exp. 69. tó a los novios ${ }^{90}$. A su cargo estuvieron las jóvenes durante el viaje hasta Madrid, siendo célebres las fiestas organizadas en la capital hispalense con este motivo, donde don Pedro protagonizó algún infortunado incidente, con fuertes desencuentros con el Concejo sevillano que llevó a algún cronista a calificarle de "imperioso" con "brusco estilo" y de formas tan desabridas como injustas ${ }^{91}$, lo cual parece encajar con su condición de absolutista. No obstante, el soberano quedó tan satisfecho que le recompensó, a petición del Ayuntamiento gaditano, con el honor de regidor de esa ciudad ${ }^{92}$.

Sus ocupaciones en palacio le permitieron estar en contacto con cuestiones que siempre le habían interesado. A su cargo se encontraba la Real Casa, lo que incluía los asuntos relacionados con la "...Cámara, Capilla, Caballerizas, Palacios, Jardines y terrenos de recreo..." ${ }^{\prime 93}$ y de ahí la abundante documentación que gestionó vinculada a las obras y mantenimiento de los palacios de San Ildefonso, Riofrío o Valsaín ${ }^{44}$, las nóminas de los empleados de la Real Academia de San Fernando, con la que estaba en contacto con frecuencia ${ }^{95}$, el funcionamiento de la Real Fábrica de Cristales de San Ildefon$\mathrm{so}^{96} \mathrm{O}$ el decoro de la Capilla Real, su amueblamiento, adorno y protocolo ${ }^{97}$, así como el incipiente Museo Nacional de Pintura y Escultura $^{98}$. Asimismo, intervenía a la hora de encargar la estampación de grabados con

${ }^{90}$ José Velázquez y Sánchez, Anales de Sevilla (Sevilla: Imprenta y Librería de Hijos de Fe, 1872), 190-193.

${ }^{91}$ Velázquez y Sánchez, Anales..., 206-207.

${ }^{92}$ Gazeta de Madrid, 21 de enero de 1817.

${ }^{93}$ López Sánchez, La mano del rey..., 131-135.

${ }^{94}$ AGP, RSSI, 23066, exp. 2; 23067, Exp. 1, etc.

${ }^{95}$ AGP, REI RF7, 279, Exp. 5.

${ }^{96}$ AGP, REI RF7, 702, Exp. 3; 750, exp. 1, etc.

${ }^{97}$ AGP, REI RF7, 425, Exp. 20; 427, exp. 11, etc.

${ }^{98}$ Archivo del Museo Nacional del Prado (AMNP), c. 357 , leg. 11202 , exp. 7, 8; c. 915 , leg. 35.01 , exp. 2 ; c. 1470, exp. 1, etc. 
los retratos de los soberanos ${ }^{99}$ o la gestión de cuestiones tan delicadas como la sustracción de diversos cuadros de los palacios reales que fueron puestos a la venta en París por "el Griego Psimary", entre los que figuraban obras de Correggio o Tiziano ${ }^{100}$, actuando el conde de enlace con la Academia ${ }^{101}$.

En este tiempo también mantuvo una estrecha relación con el arquitecto mayor, Isidro González Velázquez, a cuyo cargo estaba la obra de la Plaza de Oriente. Precisamente, rubricado por el conde de Miranda, se conserva un memorial en el que se traza el programa de intenciones que debería regir en una obra tan compleja, en el que indica que "[c]omo carezco de conocimiento de arquitectura no me atrevo a presentar dibujos para la fachada del teatro y si solo ideas para los edificios de la plaza..."102. La autoría de este documento ha sido discutida por los investigadores que han estudiado este conjunto urbanístico, habiéndolo atribuido algunos al duque de San Carlos, antecesor de don Pedro en el cargo de mayordomo mayor ${ }^{103}$. Sin embargo, la rúbrica no deja lugar a dudas y, así, lo reconoce Martínez Díaz, quien, por su parte, considera que este debe expresar los argumentos del propio arquitecto en la definición del proyecto ${ }^{104}$ (Fig. 10).

Con González Velázquez tuvo ocasión de seguir tratando, en 1818, con motivo de las obras que se llevaban a cabo en el Colegio de María de Aragón, para transformar

${ }^{99}$ AGP, REI RF7, 330, Exp. 18.

\section{${ }^{100}$ AGP, REI RF7, 547/18.}

${ }^{101}$ Esperanza Navarrete Martínez, La Academia de Bellas Artes de San Fernando y la pintura en la primera mitad del siglo XIX (Madrid: Fundación Universitaria Española, 1999), 355.

${ }^{102}$ AGP, REI RF7, 358/1.

${ }^{103}$ Jorge Maier Allende, “Remodelación urbanística durante el siglo XIX: la creación de la Plaza de Oriente" en Plaza de Oriente: Arqueología y evolución urbana (Madrid: Ayuntamiento de Madrid, 1998), 151-155.

104 Ángel Martínez Díaz, “El Palacio Real nuevo y su entorno", en Isidro Velázquez 1765-1850. Arquitecto del Madrid fernandino (Madrid: Ayuntamiento de Madrid, 2009), 64 .

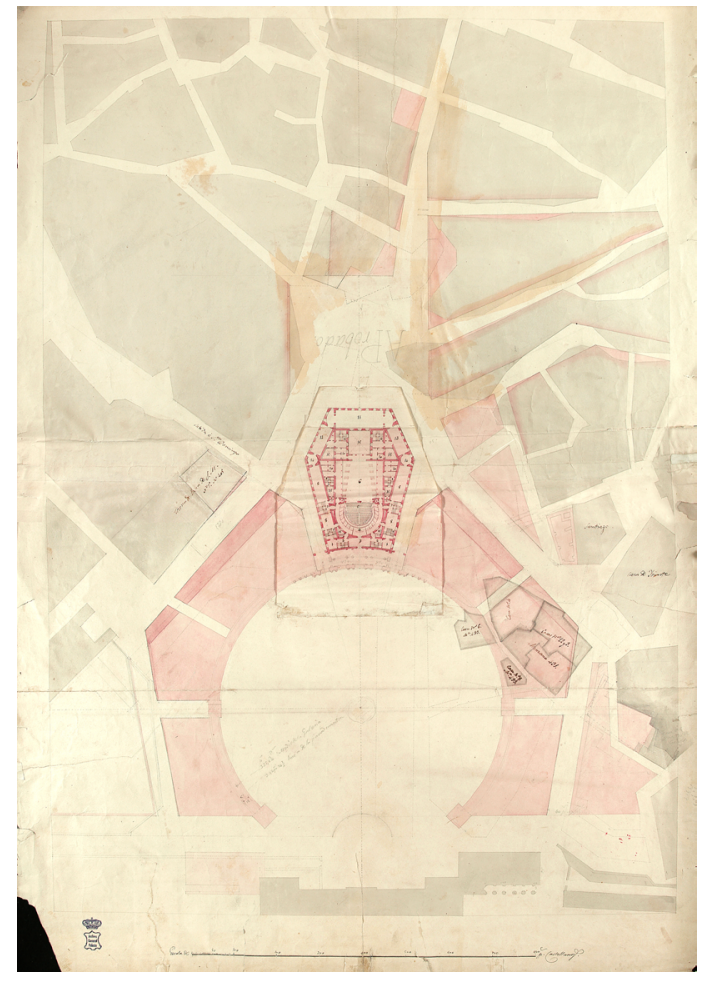

- Fig. 10. Isidro González Velázquez. Diseño para la Plaza de Oriente. Archivo General de Palacio, P00000025 (C) Patrimonio Nacional

el templo en iglesia patriarcal ${ }^{105} \mathrm{y}$, un año después, en la realización del suntuoso túmulo erigido en la iglesia de San Francisco el Grande para presidir las exequias de la reina Isabel ${ }^{106}$. No es extraño, entonces, que el conde manifestara interés en el mundo de la cultura y las artes y que cuando, en 1819, se descubrió en su Quinta de Carabanchel un mosaico romano, informara a la Real Academia de la Historia, procediendo a "...cercarlo y cubrirlo oportunamente, para ponerlo a salvo de la destrucción que en otro caso le amenazaba" 107.

${ }^{105}$ AGP, REI RF7, 258/1. Sobre ello, Rafael Lazcano González, “Colegio de doña María de Aragón (Madrid): de los orígenes a la desamortización de Mendizábal", en La desamortización: el expolio del patrimonio artístico y cultural de la Iglesia en España (Madrid: Ediciones Escurialenses, 2007), 406-407.

${ }^{106}$ Gazeta de Madrid, 30 de marzo de 1819.

${ }^{107}$ José Amador de los Ríos y Juan de Dios de la Rada y Delgado, Historia de la villa y corte de Madrid (Madrid: Ferrá de Mena, 1860) I, 85; Juan de Dios de la Rada y Delgado, "Mosaico romano de la Quinta de los Cara- 
Todo lo expuesto revela el poder alcanzado por el XV conde de Miranda y su singular transcendencia en la vida de la corte. Esta es la imagen de dignidad y autoridad con la que quiso ser retratado tras la concesión del Toisón, volviendo a recurrir a Agustín Esteve para su realización (Fig. 11). En este lienzo, que debe fecharse en 1817, don Pedro aparece representado con porte distinguido y uniforme militar junto a una mesa de despacho con libros y útiles de escritura captados con la minuciosidad propia del autor. Tanto el papel que muestra en la mano, como un libro y un documento sobre el escritorio están relacionados con la Asociación del Buen Pastor ${ }^{108} \mathrm{y}$ avalan cómo to-

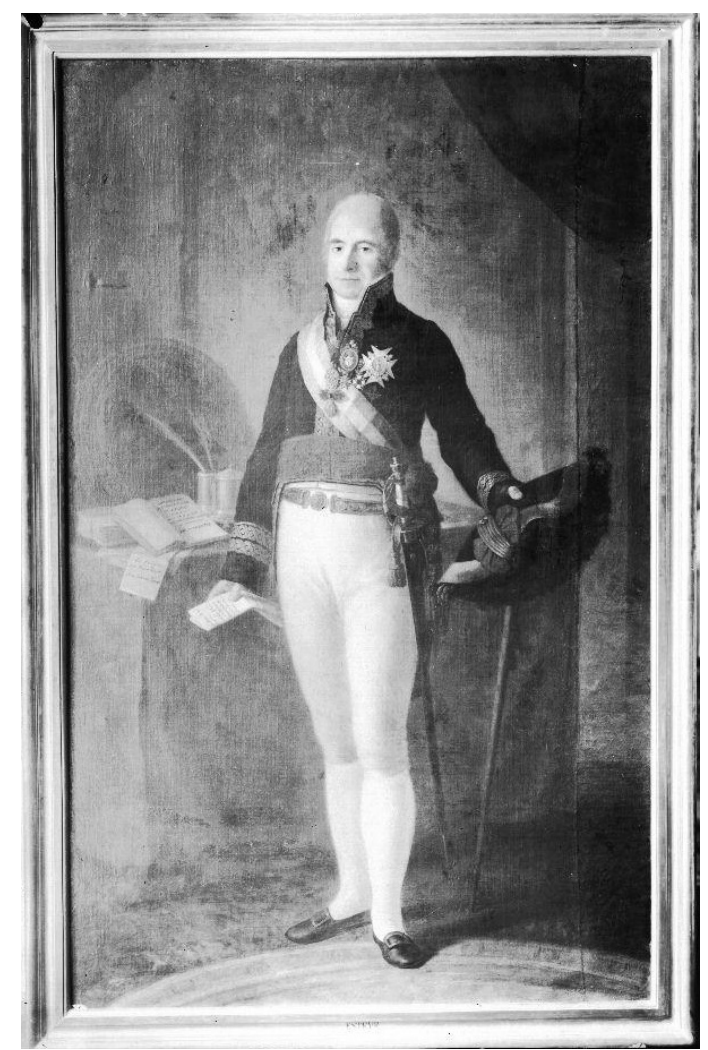

- Fig. 11. Agustín Esteve. Retrato de Pedro de Alcántara Álvarez de Toledo, XV conde de Miranda (1817). Fototeca del Instituto de Patrimonio Histórico, Moreno, 931B (Subdirección General de Coordinación Bibliotecaria, Ministerio de Cultura. Licencia Creative Commons)

bancheles, propiedad de la Excma. Señora Condesa de Montijo", Museo Español de Antigüedades, vol. VII (1876), 413-418.

${ }^{108}$ Soria, Agustín Esteve..., 142. davía, en fecha tan tardía, se sentía identificado con una empresa ilustrada que utilizó a modo de referente personal, permitiendo que la importancia del individuo se imponga a la del linaje.

Sin embargo, la fortuna de los condes cambió con motivo del Trienio Liberal pues, aunque don Pedro expresó la necesidad de adaptar el organigrama cortesano a las normas constitucionales ${ }^{109}$, quedó apartado del cargo de mayordomo ${ }^{110}$. Pasado este periodo, fue repuesto en el mismo, en julio de 1823, ostentándolo hasta su fallecimiento, el 7 de julio del año siguiente (Fig. 12) ${ }^{111}$. Don Pedro fue enterrado, no ya en la parroquia a la que los Miranda habían estado vinculados, la de los santos Justo y Pastor -actual basílica de San Miguel-, sino en el campo santo erigido en tiempos de José I, en Carabanchel, el cementerio de San Isidro ${ }^{112}$, claro ejemplo de los nuevos hábitos que tanto estaba constando imponer en el país ${ }^{113}$.

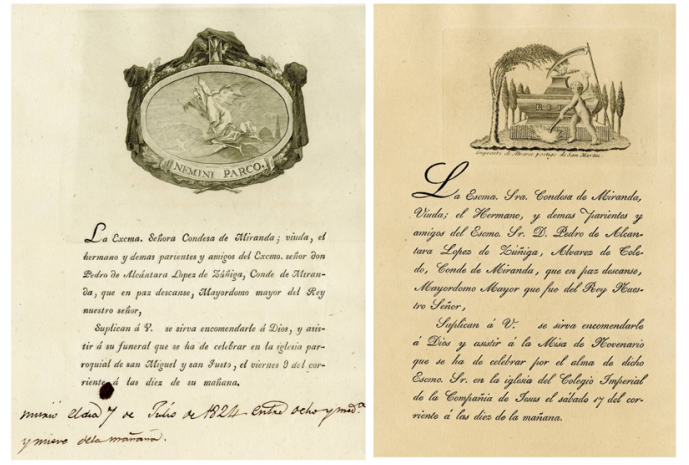

- Fig. 12. Recordatorios del funeral del XV conde de Miranda (1824). Archivo General de Palacio, PER/686, 4 (C) Patrimonio Nacional

${ }^{109}$ Antonio Manuel Moral Roncal, "Del Rey abajo, ninguno. La depuración política de la Real Casa y Patrimonio durante la crisis del Antiguo Régimen (18141835)", Historia Contemporánea, nº 29 (2004), 904-905.

${ }^{110}$ AGP, PER, 686/4.

${ }^{111}$ AGP, PER, 686/4.

${ }^{112}$ AGP, PER, 686/4.

${ }^{113}$ Carlos Saguar Quer, "El cementerio de la sacramental de San Isidro: un Elíseo romántico en Madrid", Goya: revista de arte, oํ 202 (1987) 111-120. 
Fallecía sin herederos y su viuda, la condesa, solicitó permiso para contraer matrimonio con su joven criado, José Martínez Yanguas ${ }^{114}$, en una acción que constituye un elocuente testimonio de los cambios de la sociedad del momento. A su muerte, el 4 de noviembre de 1829, los títulos y los mayorazgos pasaron a Eugenio de Palafox y Portocarrero, VII conde de Montijo, hijo de su prima María Francisca de Sales Portocarrero. De este modo se puso fin al linaje de los Zúñiga tras cuatro siglos de historia $\mathrm{y}$, con ello, sus apuestas y promociones quedarían relegadas a un segundo plano, en un contexto en el que las transformaciones políticas y sociales exigirán una renovación del papel que la nobleza debería desempeñar respecto a su política artística o de las nuevas lecturas que, avanzado el ochocientos, reformularán el sentido de sus antiguas colecciones ${ }^{115}$.

\section{BIBLIOGRAFÍA}

Albarrán, Virginia. "Goya y el refinamiento femenino en el siglo XVIII" en Goya y la corte ilustrada, 128-163. Madrid: Museo Nacional Del Prado, Museo de Bellas Artes de Bilbao y Obra Social La Caixa, 2017.

Alonso Ruiz, Begoña. “De la capilla gótica a la renacentista: Juan Gil de Hontañón y Diego de Siloé en La Vid". Anuario del Departamento de Historia y Teoría del Arte, no 15 (2003), 45-57.

Amador de los Ríos, José y Juan de Dios de la Rada y Delgado Historia de la villa y corte de Madrid. Madrid: Ferrá de Mena, 1860.

Andrés, Gregorio de. "Los códices del conde de Miranda en la Biblioteca Nacional". Revista de Archivos, Bibliotecas y Museos, vol. LXXXII, no 4 (1979), 611-627.

Ansón Navarro, Arturo. Los Bayeu, una familia de artistas de la Ilustración. Zaragoza: Caja Inmaculada, 2012.

\footnotetext{
${ }^{114}$ AHN, Estado, leg. 6390, no 225. Año 1826.

${ }^{115}$ Urquízar Herrera, “Las obras...”, 203-211.
}

Añón, Carmen. Real Jardín Botánico de Madrid: sus orígenes, 1755-1781. Madrid: Consejo Superior de Investigaciones Científicas, 1987.

Bédat, Claude. La Real Academia de Bellas Artes de San Fernando (1744-1808). Madrid: Fundación Universitaria Española, 1989.

Cadiñanos Bardeci, Inocencio. "Actuación de Ventura Rodríguez en la provincia de Burgos". Archivo Español de Arte, vol. LIX, no 233 (1986), 53-68.

Cadiñanos Bardeci, Inocencio. "El arquitecto Manuel Martín Rodríguez, discípulo de Ventura Rodríguez". Academia: Boletín de la Real Academia de Bellas Artes de San Fernando, $\mathrm{n}^{\mathrm{o}} 71$ (1990), 411-480.

Carazo Lefort, Eduardo. "El palacio de los condes de Miranda en Peñaranda de Duero". Academia. Boletín de la Real Academia de Bellas Artes de San Fernando, nº 85 (1995), 505-544.

Carrión González, Luis. Historia documentada del convento Domus Dei de La Aguilera. Madrid: Prensa Ibérica, 1930.

Constituciones de la Real Asociación de Caridad establecida para alivio de los pobres presos en las cárceles de Madrid, con la advocación del Buen Pastor. Madrid: Imprenta de la Viuda de Ibarra, 1799.

Constituciones y ordenanzas para el gobierno de los Reales Hospitales General y de la Passión de Madrid. Madrid: Antonio Marín, 1760.

Cruz Yábar, M. ․ Teresa. "Los retablos de Ventura Rodríguez", en Ventura Rodríguez, arquitecto de la Ilustración, 169-206. Madrid: Comunidad de Madrid, 2018.

Demerson, Paula de. María Francisca de Sales Portocarrero (condesa de Montijo). Una figura de la Ilustración. Madrid: Editora Nacional, 1975.

Fernández Quintanilla, Paloma. La IX duquesa de Osuna. Una ilustrada en la corte de Carlos III. Madrid: Doce Calles, 2017. 
Gómez Martínez, Javier. El gótico español de la Edad Moderna. Valladolid: Universidad de Valladolid, 1998.

González Heras, Natalia. “De casas principales a palacio. La adaptación de la residencia nobiliaria madrileña a una nueva cotidianeidad". Revista de Historia Moderna. Anales de la Universidad de Alicante, $\mathrm{n}^{-} 30$ (2012), 47-66.

Ibáñez Pérez, Alberto C. "La introducción del Neoclasicismo en Burgos: retablos y escultura". Academia: Boletín de la Real Academia de Bellas Artes de San Fernando, 69 (1989), 63-90.

Iglesias Rouco, Lena S. y María José Zaparaín Yáñez. "El monasterio de San Pedro de Cardeña, centro dinamizador del desarrollo artístico burgalés en los primeros decenios del siglo XVIII. Aportación a su estudio". Boletín de la Institución Fernán González, vol. LXXVIII, no 220 (2000), 107140.

La Parra, Emilio. Manuel Godoy. La aventura del poder. Barcelona: Tabula Tusquets, 2002.

Lazcano González, Rafael. “Colegio de doña María de Aragón (Madrid): de los orígenes a la desamortización de Mendizábal", en La desamortización: el expolio del patrimonio artístico y cultural de la Iglesia en España, 369-411. Madrid: Ediciones Escurialenses, 2007.

León Tello, Francisco José y M $\mathrm{M}^{\mathrm{a}}$ Virginia Sanz Sanz. Estética y teoría de la arquitectura en los tratados españoles del siglo XVIII. Madrid: Consejo Superior de Investigaciones Científicas, 1994.

Llanos y Torriglia, Félix de. María Manuela Kirkpatrick, condesa de Montijo. Madrid: Espasa-Calpe, 1932.

López Sánchez, María del Carmen. La mano del rey: el mayordomo mayor en la Casa Real del siglo XIX. Madrid: Universidad Carlos III de Madrid, 2017.

Maier Allende, Jorge. “Remodelación urbanística durante el siglo XIX: la creación de la Plaza de Oriente" en Plaza de Oriente: Arqueología y evolución urbana, 143-166. Madrid: Ayuntamiento de Madrid, 1998.

Martínez Díaz, Ángel. “El Palacio Real nuevo y su entorno", en Isidro Velázquez 17651850. Arquitecto del Madrid fernandino, 157-204. Madrid: Ayuntamiento de Madrid, 2009.

Mena Marqués, Manuela B. y Gudrun Maurer. La duquesa de Alba, "musa" de Goya: el mito y la historia. Madrid: El Viso, 2006.

Molina, Álvaro. Mujeres y hombres de la Espana ilustrada. Identidad, género y visualidad. Madrid: Cátedra, 2013.

Morais Vallejo, Emilio. "Formas góticas en la arquitectura del Barroco en la provincia de Burgos". Boletín del Seminario de Estudios de Arte y Arqueología, no 79 (2013), 117-142.

Moral Roncal, Antonio Manuel. "Del Rey abajo, ninguno. La depuración política de la Real Casa y Patrimonio durante la crisis del Antiguo Régimen (1814-1835)". Historia Contemporánea, no 29 (2004), 895928.

Muñoz Jiménez, José Miguel. “Barroco y peregrinación: el santuario de San Pedro Regalado en La Aguilera". Goya: revista de arte, $\mathrm{n}^{-} 228$ (1992), 330-336.

Navarrete Martínez, Esperanza. La Academia de Bellas Artes de San Fernando y la pintura en la primera mitad del siglo XIX. Madrid: Fundación Universitaria Española, 1999.

Nicolás Martínez, M. a del Mar. "Sobre la procedencia de los paisajes de José de Ribera de la colección Casa de Alba y otras noticias". Archivo Español de Arte, vol. LXXXIX, no 355 (2016), 317-325.

Nicolau Castro, Juan. "Modelo de Ventura Rodríguez para el transparente de la Catedral de Cuenca". Academia. Boletín de la Real Academia de Bellas Artes de San Fernando, no 91 (2000), 51-54.

Noticia del estado de las cárceles de Filadelfia. Madrid: Imprenta Real, 1801. 
Núñez Olarte, Juan Manuel. El Hospital General de Madrid en el siglo XVIII: actividad médico-quirúrgica. Madrid: Consejo Superior de Investigaciones Científicas, 1999.

Ortega Vidal, Javier, José Luis Sancho Gaspar y Francisco Javier Marín Perellón. Ventura Rodríguez. El poder del dibujo. Madrid: Comunidad de Madrid, 2018.

Pascual, Ricardo. El botánico José Quer (16951764): primer apologista de la ciencia española. Valencia: Instituto de Historia de la Medicina, 1970.

Payo Hernanz, René J. “De los esplendores barrocos a las luces de la razón: retablos y esculturas del siglo XVIII en la Ribera del Duero". Biblioteca: estudio e investigación, no 20 (2005), 293-342.

Payo Hernanz, René J. y José Matesanz del Barrio. "La presencia del maestro arquitecto fray José de San Juan de la Cruz en Castilla", en Fray José de San Juan de la Cruz y el arte rococó en La Rioja, 109-176. Logroño: Instituto de Estudios Riojanos, 2018.

Puerto Sarmiento, Francisco Javier. La ilusión quebrada. Botánica, sanidad y política científica en la España Ilustrada. Madrid: Consejo Superior de Investigaciones Científicas, 1988

Rada y Delgado, Juan de Dios de la. "Mosaico romano de la Quinta de los Carabancheles, propiedad de la Excma. Señora Condesa de Montijo". Museo Español de Antigüedades, vol. VII (1876), 413-418.

Redondo Cantera, M. ․ José. "La situación profesional de la arquitectura y los arquitectos en Valladolid durante el reinado de Carlos III", en 1992. El arte español en épocas de transición. Actas del IX Congreso Nacional de Historia del Arte, 53-62. León: Universidad de León, 1992.

Rodríguez Romero, Eva J. El jardín paisajista y las quintas de recreo de los Carabancheles: la posesión de Vista Alegre. Madrid: Fundación Universitaria Española, 2000.
Rodríguez Ruiz, Delfín. “José de Hermosilla. Arquitecto", en José de Hermosilla y Sandoval, 17-48. Badajoz: Diputación Provincial de Badajoz, 2015.

Saguar Quer, Carlos. "El cementerio de la sacramental de San Isidro: un Elíseo romántico en Madrid". Goya: revista de arte, no 202 (1987), 111-120.

Soria, Martín S. Agustín Esteve y Goya. Valencia: Institución Alfonso El Magnánimo y Diputación Provincial de Valencia, 1957.

Soria Mesa, Enrique. La nobleza en la España moderna. Cambio y continuidad. Madrid: Marcial Pons, 2007.

Urriagli Serrano, Diana. “Coleccionismo de pintura en España en la segunda mitad del siglo XVIII", en El arte español entre Roma y París (siglos XVIII y XIX). Intercambios artísticos y circulación de modelos, 239240. Madrid: Casa de Velázquez, 2014.

Urquízar Herrera, Antonio. "Las obras de arte en la supresión de los mayorazgos: el debate parlamentario y el pleito por la testamentaría de la XIII duquesa de Alba (1802-1844)". Boletín de Arte, no 37 (2016), 203-211.

Urquízar Herrera, Antonio y José Antonio Vigara Zafra. "La nobleza española y Francia en el cambio de sistema artístico, 1700-1850", en El arte español entre Roma y París (siglos XVIII y XIX). Intercambios artísticos y circulación de modelos, 257-274. Madrid: Casa de Velázquez, 2014.

Velázquez y Sánchez, José. Anales de Sevilla. Sevilla: Imprenta y Librería de Hijos de Fe, 1872.

Verdú Ruiz, Matilde. La obra municipal de Pedro de Ribera. Madrid: Ayuntamiento de Madrid, 1988.

Vigara Zafra, José Antonio. “El palacio del VI conde de Fernán Núñez. La arquitectura como exaltación simbólica del linaje durante la Ilustración", Tiempos Modernos, 29 (2014). 
Zaparaín Yáñez, M. José. “El patronato del conde de Miranda en la iglesia colegial de Peñaranda de Duero, 1728-1732", en Patronos, promotores, mecenas y clientes. VII Congreso Nacional de Historia del Arte, 581-588. Murcia: Universidad de Murcia, 1992.

Zaparaín Yáñez, M. ${ }^{a}$ José. El monasterio de Santa María de La Vid: arte y cultura. Del medievo a las transformaciones arquitectónicas de los siglos XVII y XVIII. Madrid: Religión y Cultura, 1994.

Zaparaín Yáñez, M. ․ José. Desarrollo artístico de la comarca arandina. Siglos XVII y XVIII. Burgos: Diputación Provincial de Burgos, 2002.

Zaparaín Yáñez, M. José. “De la herencia barroca a la racionalización de la viven- cia espiritual: las fábricas religiosas". Biblioteca: estudio e investigación, 20 (2005), 253-292.

Zaparaín Yáñez, M. a José. “Con otros ojos. La promoción nobiliar femenina en la Ribera burgalesa del Duero. Siglos XVI y XVII". Biblioteca: estudio e investigación, $\mathrm{n}^{\mathrm{o}}$ 28 (2013), 261-298.

Zaparaín Yáñez, M.ํㅗ José y Juan Escorial Esgueva. "María de Zúñiga y Avellaneda. VI condesa de Miranda. Linaje, promoción artística y devoción en los umbrales del Barroco", en El Barroco: universo de experiencias, coordinado por $\mathrm{M}^{\mathrm{a}}$ del Amor Rodríguez Miranda y José Antonio Peinado Guzmán, 203-223. Córdoba: Hurtado Izquierdo, 2017. 